usually be recovered in pure cultures from the lesions produced. In cases where vaccines are desired, we determine by this means which strain of organism to use, rather than make it from a mixed culture.

Dr. Seibel: I am referring to heart lesions where the diplococcus is present and that same coccus found in the lung, and in another case where the organism was also the diplococcus, and I was wondering whether there was an affinity there for certain species of the diplococcus.

Dr. Meisser: Because diplococci harbored by infected teeth may be the cause of an endocarditis in one patient does not mean that the same type of diplococci will cause an endocarditis in all patients who harbor such organisms. A streptococci viridans in the infected tooth or granuloma of one patient may acquire a specificity for joints while in others it may acquire a specificity for muscle tissue, kidneys, heart tissues, and so forth. We cannot tell by a microscopic examination what the specificity of certain streptococcus may be.

Two of the experiments which I cited are of special interest because they emphasize more than any others that results in animals are due to the elective affinity of the organisms and not to number of bacteria injected. In the one case, we produced a marked iritis, arthritis and myositis in animals both by intravenous injection and by the injection of but few organisms into the anterior chamber of the eye.

The lesions in the animals injected into the anterior chamber of the eye were as marked as those produced in the animals which were intravenously injected with large doses of the same organism. In the other case we produced nephritis both by intravenous injection of rabbits and by the devitalization and infection of two cuspids in dogs with a staphylococcus from a patient's foci. The condition experimentally produced in these dogs was very similar to that so often found in man, not an overwhelming infection, but only a few infected teeth. The nephritis produced in these dogs from the infections about the teeth was as severe as that produced in the rabbits by the intravenous injection of large doses of the same organism.

\title{
THE RELATION OF THE GENERAL PRACTITIONER OF DENTISTRY AND THE PEDIADONTIST
}

\author{
By PHILIP R. THOMAS, D.D.S., Minneapolis, Minnesota
}

(Read before the North Suburban Branch of the Chicago Dental Society, Evanston, Illinois, January 17,1922 )

$\mathrm{T}$ $\mathrm{HE}$ relation between the pediadontist and the general practitioner is of an entirely different character from that of the other different specialties in dentistry. The radiodontist and the exodontist in referred cases, terminate their relations with the patient in so far as their services are indicated. A case is referred to the orthodontist for a definite service covering the time required to accomplish and attain a certain orthodontic result. During this time, which may be for six months or a longer period, the pa- tient is in touch with his own dentist and returns to him for any required dental service. A patient referred to the pediadontist is in an entirely different situation in that the service rendered by the pediadontist covers a longer period of time than any other referred cases. In other words the patient is referred to the pediadontist for a long period of time for general dental supervision, usually until the age of twelve is reached. In my experience most patients referred to the pediadontist is the unmanageable kind. 
Many do not do anything for the children and apparently are not willing to let the other fellow try. Some of the following reasons are given for this attitude on the part of the profession:

Fear of losing the patient forever.

Fear of losing the rest of the family if the children are referred.

Indifference to the welfare of the child.

Lack of willingness to admit that the other fellow has any special ability in the care of children.

A desire to do everything of every kind in dentistry for the family.

A lack of agreement as to the methods of procedure.

Lack of agreement relative to diagnosis for examples as related to orthodontia and time when treatment should be started, or as related to means of eliminating focal infection.

The pediadontist is faced with many problems in relation to patients referred to him. The value of his service is minimized by the attitude of the general practitioner toward children's work. Consequently he must spend half of his time educating parents so that he can get enough for his service to make it possible to continue practice. The following experience will illustrate. A bill of $\$ 4.00$ was sent to the mother in a case for consultation and prophylaxis. A letter came back saying that the bill was outrageous; that her own dentist upheld her and offered to care for the child's deciduous teeth free of charge. What sort of care would that child get for nothing and how will the dentist pay his bills? Another illustration: Two children presented for treatment accompanied by a governess. They came in a limousine. Consultation, amalgam fillings, and prophylaxis for both was the servlui given. The bill - rendered was $\$ 10.00$ and $\$ 12.00$ respectively. A total of $\$ 22.00$. A letter about as follows was received: "My wife has referred your bill to me for adjustment. After much thought I think the following would be about right:

"Cleaning Bernadette's teeth.......... $\$ 3.00$

"Cleaning Frank's teeth.................. 3.00

"Some small fillings......................... 3.00

"Extracting baby teeth which might

have been pulled at home.

$$
\text { "Total }
$$

"I herewith tender my check for $\$ 12.00$ trusting it may be satisfactory."

What is a pediadontist and what training and knowledge should he have? A pediadontist is a dentist limiting his efforts in his profession to children from infancy to adolescence. He should preferably have some years of training in the solution of the problems arising in general practice that he may know the sequelae or oral conditions as seen in the child's mouth. With such experience as a foundation he should direct his study to all factors concerned in the development of normal dentition and the maintenance of normal oral health. This makes it incumbent on the pediadontist to recognize the diseases of the sinuses, the eyes, ears, nose and throat which are related to his work. Congenital lues, rachitis, dermatitis, malnutrition, otitis media, deafness, iritis, conjunctivitis, stenosis of the nares, diverted septum, and the diseases of the throat are among the many conditions presented in practice, and must be diagnosed for reference to the medical specialist. Nothing widens and broadens the viewpoint of the pediadontist more than visits and observation in the children's operating rooms and wards of hospitals, as well as the private clinics of the medical specialist. A knowledge of the etiology, diagnosis, and sequelae of the diseases of childhood will add largely to the usefulness of the pediadontists. A knowledge of the principles of immunity, oral infection in the mouth of the child in its relation to the health of the child, together with the study of 
nutrition and dietetics applies fundamentally to the work of the pediadontist. The etiology and treatment of malocclusion in its incipiency he' must be thoroly conversant with, together with oral surgery in its application to children. Pediadontia as I see it, is a much wider field of usefulness than that conveyed to the mind of the dental profession by the term "children's dentistry." This, in the minds of the profession means filling, extracting, and prophylactic treatment of the child's teeth. As I see it the pediadontist to properly function must have a much broader training. He must have a desire and the ability to give to his patients a well-rounded out health service as indicated above, not necessarily all performed by himself but such service rendered through his instrumentality because of proper training and study. Through his interest in children he must become an important factor in the solution of our problem of public oral health education. The pediadontist must concern himself not only with the restoration of mouth lesions including the teeth, but must within the limits of his degree assume his share of responsibility not only for prevention of dental lesions but systemic lesions as well.

In the development of any field of endeavor much trouble may be expected. In all cases the pediadontist must be careful not to say or do anything to undermine or weaken the standing of his fellows. He must be willing to acknowledge his limitations in restorative work in children's teeth. He must be willing to assume responsibility for service rendered. He must study his subject that he may have proper judgment in his work. He must realize that pediadontia is to dentistry, what pediatrics is to medicine. $\mathrm{He}$ must visualize the splendid possibilities and opportunties before him for doing a wonderful work for humanity. He must realize that the most virgin field for research in dentistry lies before him and he must strive to develop it. He must give freely of his knowledge and methods to his fellow-practitioners that all children may benefit therefrom. He must be in dentistry the friend of every child. The influence of the love of children, the daily contact with them, the helpfulness of service in their happiness and health can have no other than a refining, uplifting, humanizing effect on any professional man or woman. If the pediadontist truly loves his work and his patients, his relations with his fellow-practitioners can be none other than ethical, upright, and honorable. Most of all that he may properly dignify his special work in the eyes of the profession, he must have ideals, for prevention in dentistry is idealism in dentistry. 